\title{
Protocatechuic Acid Abrogates Oxidative Insults, Inflammation and Apoptosis in Liver and Kidney Associated With Monosodium Glutamate Intoxication in Rats
}

Rami B. Kassab

Helwan University Faculty of Science

Abdulrahman Theyab

Security Forces Hospital Program Makkah

Ali O. Al-Ghamdy

Al Baha University Faculty of Science

Mohammad Algahtani

Security Forces Hospital Makkah: Security Forces Hospital Program Makkah

Ahmad H. Mufti

Umm Al-Qura University

Khalaf F. Alsharif

Taif University

Ehab M. Abdella

Beni Suef University Faculty of Science

Ola A. Habotta

Mansoura University

Mohamed M. Omran

Helwan University Faculty of Science

Maha S. Lokman

Prince Sattam bin Abdulaziz University

Amira A. Bauomy

Qassim University

Ashraf Albrakati ( $\nabla$ mchakl@hotmail.com )

Taif University College of Medicine https://orcid.org/0000-0002-4116-7865

Roua S. Baty

Taif University College of Science

Khalid E. Hassan

Taif University Faculty of Medicine

Maha A. Alshiekheid

King Saud University College of Science 


\section{Ahmed E. Abdel Moneim}

Helwan University Faculty of Science

Heba A. El Masry

Helwan University Faculty of Science

\section{Research Article}

Keywords: apoptosis, hepatorenal, monosodium glutamate, Nrf2, Nf-kB, protocatechuic acid

Posted Date: August 2nd, 2021

DOl: https://doi.org/10.21203/rs.3.rs-731074/v1

License: (c) (1) This work is licensed under a Creative Commons Attribution 4.0 International License. Read Full License

Version of Record: A version of this preprint was published at Environmental Science and Pollution Research on September 25th, 2021. See the published version at https://doi.org/10.1007/s11356-02116578-4. 


\section{Abstract}

Monosodium glutamate (MSG), a commonly used flavor enhancer, has been reported to induce hepatic and renal dysfunctions. In this study, the palliative role of protocatechuic acid (PCA) in MSG-administered rats was elucidated. Adult male rats were assigned to four groups, namely control, MSG $(4 \mathrm{mg} / \mathrm{kg}), \mathrm{PCA}$ (100 mg/kg), and the last group was co-administered MSG and PCA at aforementioned doses for seven days. Results showed that MSG augmented the hepatic (AST and ALT) and renal (urea and creatinine) functions markers as well as glucose, triglycerides, total cholesterol and LDL levels. Moreover, marked increases in MDA levels accompanied by declines in GSH levels and notable decreases in the activities of SOD, CAT, GPx, and GR were observed in MSG-treated group. The MSG-mediated oxidative stress was further confirmed by down-regulation of $N f e 2 / 2$ gene expression levels in both tissues. In addition, MSG enhanced the hepatorenal inflammatory response as witnessed by increased inflammatory cytokines (IL$1 \mathrm{~b}$ and TNF-a) and elevated NF-KB levels in both tissues. Further, significant increases in Bax (proapoptotic biomarker) levels together with decreases in Bcl-2 (anti-apoptotic marker) levels were observed in MSG administration. Hepatic and renal histopathological screening supported the biochemical and molecular findings. On the contrary, co-treatment of rats with PCA resulted in remarkable enhancement of the antioxidant cellular capacity, suppression of inflammatory mediators and apoptosis. These effects are possibly endorsed for activation of Nrf-2 and suppression of NF-kB signaling pathways. Collectively, addition of PCA counteracted MSG-induced hepatic and renal injurious effects through modulation of oxidative, inflammatory and apoptotic alterations.

\section{Introduction}

Many chemicals have been recently introduced in food technology such as colorants, preservatives, stabilizers, emulsifiers, sweeteners, and flavor enhancers (Acar). Monosodium glutamate (MSG), the sodium salt of glutamic acid, is one of the frequently used flavor enhancers (E621) to increase food palatability and taste (Mahieu et al. 2016). By acting on particular glutamate receptors in the taste buds, it enhances markedly the taste and palatability of food (Hassan et al. 2020). It elicits the "umami" taste experience that is recognized in high glutamate foods as meat, fish, cheese, and some vegetables (del Carmen Contini et al. 2017). Currently, MSG can be added to soups, processed meats, dietary supplements, and canned vegetables (Celestino et al. 2021). Despite of being reported as safe for human according to the last FDA reports, using of MSG as a food additive is still disputed (Shukry et al. 2020). Former reports have revealed that the consumption of MSG was associated with human metabolic syndrome, obesity, and arterial hypertension in addition to various damages in the liver, brain, thyroid, and kidney (Elbassuoni et al. 2018, Mekkawy et al. 2020, Nahok et al. 2019).

It was reported that MSG administration resulted in hepatocellular damage as demonstrated by increases in biomarkers of liver functions, oxidative stress, inflammation and apoptosis (Eid et al. 2019, Hassan et al. 2020). Recent studies stated that MSG evoked notable alterations in lipid profile (Shukry et al. 2020). Administration of MSG to newborn rats was accompanied by insulin resistance, increase in body weight, hyperlipidemia and hyperglycemia (Sasaki et al. 2011, Seiva et al. 2012). Moreover, chronic exposure to 
MSG evokes marked nephrotoxicity with subsequent cellular and functional damage (Sharma et al. 2014). Glomerular hypercellularity accompanied by infiltration of inflammatory cells in the kidney cortex were observed in rats injected with MSG (Dixit et al. 2014). On long-term consumption, MSG causes alkaline urine and triggers kidney stones formation with induction of tubulo-interstitial fibrosis in rats (Nahok et al. 2019). Imbalance between excessive production of free radicals and antioxidant system in cells is a major contributor to MSG-mediated hepatorenal damage (Albrahim \&Binobead 2018, Eid et al. 2019, Sharma et al. 2014). Nrf2 is a master antioxidant regulator which induces the expression of phase $\nabla$ antioxidant enzymes (Yuan et al. 2020). In response to oxidative damage, Nrf2 migrates to the nucleus to trigger the synthesis of antioxidant enzymes to overwhelm excess ROS and reducing DNA damage (ElKhadragy et al. 2021, Kassab et al. 2020). Nuclear factor-KB (NF-KB) is a vital regulator for inflammatory responses that triggers the proinflammatory gene expression as TNF- $\mathrm{a}$ and other cytokines (Kaewmool et al. 2020). Accordingly, targeting the Nrf2 and NF-KB pathways could be potent therapeutic approaches to alleviate organ damage following MSG exposure.

Protocatechuic acid (PCA), 3,4-dihydroxybenzoic acid, is a major anthocyanins metabolite that is widely detected in olives, Hibiscus sabdariffa, Salvia miltiorrhiza, white grape wine and green tea (El-Sonbaty et al. 2019, Kaewmool et al. 2020). Several studies have addressed the multifaceted biological effects of PCA as antioxidant, anti-inflammatory, anti-hyperglycemic and antiapoptotic activities (Adefegha et al. 2015, Li et al. 2021a, Li et al. 2021b). Radhiga et al. (Radhiga et al. 2016) found that PCA induced marked declines in lipid profile markers (TC, TG, free fatty acid, and phospholipids) in the plasma, liver and kidney of D-galactosamine-administered rats. Further, PCA evoked a notable hepatorenal protective effect indicated by improvement of both organ functions and structural integrity in rats treated with cadmium and D-galactosamine (Adefegha et al. 2015, Radhiga et al. 2016). Marked anti-inflammatory and antioxidative properties were also reported in PCA co-treatment against doxorubicin (Molehin et al. 2019), cadmium (Adefegha et al. 2015), methotrexate (Owumi et al. 2019), and diabetic nephropathy (Lin et al. 2011). Modulation of Nrf2 pathway was reported in PCA-injected mice with subsequent relieve of brain edema and disrupted blood brain barrier after intracerebral hemorrhage (Xi et al. 2020). Moreover, PCA provoked anti-inflammatory and anti-apoptotic activities with decreased microglial activation in lipopolysaccharide-activated BV2 cells by inhibition of the NF-KB pathway (Kaewmool et al. 2020).

Based on its beneficial effects, PCA co-treatment may be considered as a fascinating intervention to alleviate organ damage. However, to our knowledge, no previous report in the literature focused on the effect of PCA on hepatorenal damage accompanying MSG administration in rats. Therefore, it would be worthy to study the potential therapeutic activity and the possible underlying mechanisms of PCA on both liver and kidney dysfunctions associated with MSG exposure in rats. Oxidative stress, inflammatory and apoptotic biomarkers were assessed on the biochemical and molecular levels.

\section{Materials And Methods}

\section{Chemicals}


Monosodium glutamate (MSG) and PCA were purchased from Sigma-Aldrich (St. Louis, MO, USA).

\section{Exprimental animals}

Adult male Wister albino rats (150-200 grams body weight; 8-10-week-old) were obtained from VACSERA (Helwan, Cairo, Egypt) and used for this study. The housing of animals was under controlled laboratory conditions of temperature $\left(22-24^{\circ} \mathrm{C}\right)$, humidity (50 -60\%) and $12 \mathrm{~h} \mathrm{light/dark}$ cycle. During the study, rats were fed on standard rodent balanced diet and freely supplied with water.

\section{Study design and treatment protocol}

Rats $(\mathrm{N}=40)$ were assigned into four equal groups of ten rats each and orally treated with either MSG and/or PCA per day for seven days:

Group 1 (Control); rats orally received normal saline $(0.9 \% \mathrm{NaCl})$.

Group 2 (PCA); rats were administered orally with $100 \mathrm{mg} \mathrm{kg}^{-1}$ of PCA via a gavage needle for seven days according to a previous report (Li et al. 2021b).

Group 3 (MSG); rats were treated with $4 \mathrm{mg} \mathrm{kg}^{-1}$ of MSG for seven days according to a previous report (Eid et al. 2019).

Group 4 (PCA+MSG); rats were received $100 \mathrm{mg} \mathrm{kg}^{-1}$ of PCA for seven days and $4 \mathrm{mg} \mathrm{kg}^{-1}$ of MSG for another seven days.

The treatment with PCA was done 120 min before administration of MSG. After $24 \mathrm{~h}$ from the last treatment, animals were euthanized by intraperitoneal injection with 90-100 mg ketamine and $10 \mathrm{mg}$ xylazine $\mathrm{kg}^{-1}$. Blood samples were collected and allowed to coagulate for serum separation. The liver and kidney were directly dissected and divided into three parts. The first portion was utilized for preparing tissue homogenates $(10 \% \mathrm{w} / \mathrm{v})$ were equipped by mixing a specified weight of the tissue with ice-cold 50 $\mathrm{mM}$ Tris-HCl buffer $(\mathrm{pH} 7.4)$ followed by centrifuging at $3000 \times g$ for 10 min at $4{ }^{\circ} \mathrm{C}$. The resultant supernatant was stored at $-20^{\circ} \mathrm{C}$ for biochemical analysis. The second portion was kept at $-80{ }^{\circ} \mathrm{C}$ for analysis of gene expression. The third portion was preserved in $10 \%$ of neutral-buffered formalin for histopathological examination.

\section{Estimation of liver and kidney function markers}

Serum parameters of liver functions (ALT, and AST) were calorimetrically measured using standard kits (Biodiagnostic, Giza, Egypt) based on the methods described by Reitman and Frankel (Reitman \&Frankel 1957). Also, renal function markers (urea, and creatinine) were evaluated using commercial kits following the manufacturer's information. 
Levels of total cholesterol (TC) and triglycerides (TG) were estimated using standard kits (Biodiagnostic, Giza, Egypt) following the manufacturer's information. The level of serum glucose was determined according to the method described by Trinder et al. (Trinder 1969).

\section{Oxidative stress and antioxidant biomarkers}

Levels of renal and hepatic glutathione (GSH), the non-enzymatic antioxidant marker, were determined colorimetrically utilizing Elaman's reagent according to the method of by Ellman (Ellman 1959). Lipid peroxidation was assessed in terms of malondialdehyde (MDA) according the method established by Ohkawa et al. (Ohkawa et al. 1979). Measurement of the activities of superoxide dismutase (SOD) was done based on the capability of SOD to inhibit the reduction of nitroblue tetrazolium dye as reported by Sun et al. (Sun et al. 1988). In addition, catalase (CAT) activities was estimated according to the decomposition rate of $\mathrm{H}_{2} \mathrm{O}_{2}$ following the method of Aebi (Aebi 1984). GSH peroxidase (GPX), and GSH reductase (GR) were assessed by determining the oxidation rate of NADPH at $340 \mathrm{~nm}$ and reduction rate of NADPH in the presence of glutathione according to Paglia and Valentine (Paglia \&Valentine 1967), and Factor et al. (Factor et al. 1998), respectively.

\section{RNA extractions, reverse transcriptions and qRT-PCR}

Total RNA was isolated from the liver and kidney samples by TRIzol reagent (Qiagen, Germantown, MD, USA) following the manufacturer instructions. Then, the cDNA synthesis was conducted by a Super ScriptVILO cDNA Synthesis Kit (Life Technologies, Thermo Fisher Scientific, Waltham, MA, USA). Quantification of target mRNA levels were performed by qRT-PCR using SYBR Green MasterMix (Life Technologies, CA, USA) with the Applied Biosystems 7500 Instrument. Primer of the Nfe2/2 gene: forward, 5'-CAGCATGATGGACTTGGAATTG-3' and reverse 5'-GCAAGCGACTCATGGTCATC-3' were prepared by Jena Bioscience GmbH (Jena, Germany). B-actin: forward, 5'-GTCCACCCGCGAGTACAAC-3' and reverse 5'GGATGCCTCTCTTGCTCTGG-3' was used as the housekeeping gene. The alterations in gene expression compared to the control were assessed based on the standard $2^{-\Delta \Delta C t}$ method according to Pfaffl (Pfaffl 2001).

\section{Inflammatory marker determination}

Pro-inflammatory markers, i.e.; tumor necrosis factor-a, and interleukin-1 $\beta$ were assessed by ELISA kits obtained from Thermo Fisher Scientific, USA according to the manufacturer's instructions for TNF-a (Cat. no. BMS607-3) and IL-1 $\beta$ (Cat. no. BMS6002).

\section{Apoptotic biomarkers assessment}

Levels of Bax, pro-apoptotic marker, and Bcl-2, antiapoptotic marker, were estimated using commercially available ELISA kits purchased from BioVision, Inc. Manufacturers' information for (rat Bax; Cat. No.: E4513) and Cusabio (rat Bcl-2; Cat. No.: CSB-E08854r). 
Liver and kidney were fixed by immersion in neutral buffered formalin (10\%), dehydrated, embedded in paraffin wax and cut into $5 \mu \mathrm{m}$-thick sections. After that, liver and kidney sections were deparaffinized, stained with hematoxylin and eosin and examined under a Nikon Eclipse E200-LED microscope (Nikon Corporation, Tokyo, Japan) for histopathological changes.

\section{Statistical analysis}

To assess the differences between groups, one-way analysis of variance (ANOVA) followed by Duncan's Multiple Range test was employed. $P$ value was less than 0.05 was considered to be statistically different. Analyzed data were presented as the mean \pm SD.

Table (1): The effect of protocatechuic acid (PCA) on monosodium glutamate (MSG)-induced disturbance in liver and kidney functions biomarkers, glucose and lipid profile in serum samples in male rats.

\begin{tabular}{|lllll|}
\hline Parameters & CNT & PCA & MSG & PCA+MSG \\
\hline ALT (U/L) & $44.89 \pm 5.71$ & $46.41 \pm 6.24$ & $84.64 \pm 7.69^{\mathrm{a}}$ & $58.96 \pm 7.45^{\mathrm{ab}}$ \\
\hline AST (U/L) & $65.37 \pm 9.48$ & $65.37 \pm 7.22$ & $127.74 \pm 13.90^{\mathrm{a}}$ & $75.49 \pm 12.15^{\mathrm{b}}$ \\
\hline Urea (mg/dL) & $30.43 \pm 7.17$ & $28.15 \pm 5.14$ & $70.37 \pm 7.21^{\mathrm{a}}$ & $43.56 \pm 7.79^{\mathrm{ab}}$ \\
\hline Creatinine (mg/dL) & $0.52 \pm 0.11$ & $0.56 \pm 0.09$ & $0.63 \pm 0.08^{\mathrm{a}}$ & $0.58 \pm 0.07^{\mathrm{b}}$ \\
\hline Glucose (mg/dL) & $129.62 \pm 5.67$ & $120.33 \pm 12.32$ & $156.73 \pm 12.40^{\mathrm{a}}$ & $133.52 \pm 9.44^{\mathrm{b}}$ \\
\hline Total cholesterol (mg/dL) & $34.35 \pm 6.63$ & $33.05 \pm 5.21$ & $58.68 \pm 11.64^{\mathrm{a}}$ & $40.11 \pm 7.62^{\mathrm{b}}$ \\
\hline Triglyceride (mg/dL) & $107.71 \pm 15.30$ & $94.71 \pm 14.93$ & $159.52 \pm 17.02^{\mathrm{a}}$ & $121.45 \pm 16.81^{\mathrm{ab}}$ \\
\hline
\end{tabular}

Each value represents mean $\pm S D(n=7) .{ }^{a} P<0.05$ versus the control rats, ${ }^{b} P<0.05$ versus the MSGtreated rats.

\section{Results}

\section{PCA modulates MSG-induced hepatorenal dysfunction markers in rats}

As shown in Table 1, marked increases $(P<0.05)$ were noticed in enzymatic activities of AST, and ALT of as well as levels of urea and creatinine in MSG-treated rats in respect to their controls. However, rats received the treatment with PCA displayed notable declines $(P<0.05)$ in the aforementioned markers when compared with MSG-administered rats. 


\section{PCA counteracts MSG-induced alterations in glucose level and lipid profile in rats}

In comparison with the control group, notable increases $(P<0.05)$ were observed in levels of glucose, TC and TG in MSG-exposed rats. On the other hand, the administration of PCA lessened significantly $(P<$ $0.05)$ the levels of the above-mentioned markers in relation with MSG-treated group as presented in Table 1.

\section{PCA mitigates MSG-induced hepatic and renal oxidative markers in rats}

Figure 1 depicts the impact of PCA administration on biomarkers of oxidative stress in the kidney and liver of MSG-treated rats. Marked elevations $(P<0.05)$ in lipid peroxidation products represented by MDA levels were observed in MSG-exposed rats compared to the control rats. Concomitant depletion of GSH levels $(P<0.05)$ were also detected in MSG-exposed rats in respect to the control. Interestingly, in comparison with the MSG-exposed rats, notable increases $(P<0.05)$ in $\mathrm{GSH}$ levels were recorded together with decreases $(P<0.05)$ in MDA levels in both organs in rats co-treated with PCA.

\section{PCA boosts hepatic and renal antioxidant enzymatic activities in MSG-treated rats}

MSG treatment inhibited markedly $(P<0.05)$ the activities of SOD, CAT, GPx, and GR in both organs compared to the control rats which reveal the diminished antioxidant power of the cells (Fig. 2). However, the co-administration of PCA at $100 \mathrm{mg} \mathrm{kg}^{-1}$ enhanced markedly $(P<0.05)$ the enzymatic levels of SOD, CAT, GR, and GPx in liver and kidney relative to the sole treatment with MSG.

To illustrate the antioxidant potency of PCA to trigger Nrf2 pathway in hepatic and renal tissues of rats exposed to MSG, the mRNA expression of $N f e 2 / 2$ were assessed in both organs of the tested groups (Fig. 3). Compared to control, MSG administration provoked significant down-regulations $(P<0.05)$ in the mRNA expression of $N f e 2 / 2$ in liver and kidney of treated rats. However, the co-treatment of rats with PCA induced notable increases $(P<0.05)$ in $N f e 2 / 2$ expression related to the rats received only MSG.

\section{PCA exerts anti-inflammatory effect in hepatic and renal tissues of MSG-treated rats}

As displayed in Fig. 4, MSG treatment obviously prompted inflammatory reactions indicated by substantial increases $(P<0.05)$ in levels of TNF-a, and IL-1 $\beta$ in hepatic and renal tissues compared to control. Notably, concomitant treatment with PCA statistically $(P<0.05)$ relieved the levels of tested cytokines in relation with MSG-treated rats. 
Due to the crucial role of NF-KB signaling pathway in activation of inflammatory mediators, the effect of PCA and MSG exposure on NF-KB was investigated. As illustrated in Fig. 4, marked increases $(P<0.05)$ in levels of NF-KB in hepatic and renal tissues in MSG group related to the control group. On the contrary, PCA co-treatment halted the activation of NF-KB in both organs as indicated by lower NF-kB levels $(P<$ 0.05) than those of MSG-treated group.

\section{PCA lessened MSG-induced hepatic and renal apoptotic changes in rats}

Rats exposed to MSG showed significant higher levels of Bax, proapoptotic marker, in hepatic and renal tissues than those in the control as shown in Fig. 5. In contrast, MSG induced significant decreases $(P<$ $0.05)$ in Bcl-2, antiapoptotic marker, in liver and kidney compared to control rats. Upon pretreatment with PCA, noticeable decreases $(P<0.05)$ in Bax levels concomitant with increases $(P<0.05)$ in Bcl-2 levels were observed compared to the MSG-intoxicated rats. These findings revealed the anti-apoptotic effect of PCA in rats treated with MSG.

PCA abrogates the histopathological alterations in liver and kidney of MSG-treated rats

Histopathological screening of hepatic tissue of the control and PCA-administered rats showed typical hepatic histoarchitecture with central vein and well-arranged hepatocytes (Figs. 6A and 6B, respectively). In contrast, liver sections of the MSG-treated rats displayed marked dilatation in the central vein and blood sinusoids in addition to disarrangement of the hepatic strands with many fat bodies. Hepatocytic vacuolation, infiltration of massive inflammatory cells and enlarged detached Kupfer cells were also noticed. Additionally, there were abundant small fragmented pyknotic nuclei and apoptotic hepatocytes (Fig. 6C). Interestingly, the co-treatment of rats with PCA efficiently alleviated the hepatic lesions, indicate the substantial protective effect of PCA against MSG-mediated injury (Fig. 6D).

Histopathological features of the kidney sections in the control and PCA-treated rats unveiled the normal structure of the glomerulus and tubules without any damage (Figs. 7A and 7B, respectively).

Nevertheless, kidney tissue of the MSG-treated rats exhibited marked swelling in the glomeruli, decreased Bowman's spaces, and vacuolar degeneration in addition to infiltration of inflammatory cells in the interstitial tissue. Cellular debris were observed in the tubular lumen together with cell desquamation (Fig. 7C). Notably, co-treatment with PCA protected renal tissue as evidenced by the normal histological architecture of renal glomeruli and tubules (Fig. 7D).

\section{Discussion}

Because of their responsibility for the detoxification of toxic compounds, marked alterations in functions and structure of liver and kidney have been detected after MSG administration for seven days. After being absorbed, MSG is converted into sodium ion and L-glutamate. The glutamate receptors are abundant in central nervous system, as well as other organs as lungs, spleen, ovaries, liver, kidneys and heart (Gill \&Pulido 2001). When these receptors are overstimulated by glutamate or glutamate analogs, this could 
result in ROS production, lipid peroxidation and triggering the caspase cascade due to $\mathrm{Ca}^{2+}$ influx (Mirzakhani et al. 2020). Accordingly, these changes can lead to organ dysfunction and enzymatic disturbances. Additionally, after dissociation of MSG to glutamate, it produces ammonium ions by oxidative deamination. Detoxification of ammonium ion is done in the liver via the urea cycle. Therefore, excess ammonium ion followed the MSG consumption could induce liver damage (Hassan et al. 2020).

Regarding the serum biochemical results, our study revealed significant increases in serum ALT and AST levels in MSG-treated group. These results are in agreement with former studies (Albrahim \&Binobead 2018, Shukry et al. 2020). Transaminases are liver function indicators as they are released into the blood circulation in cases of hepatocellular damage (Al Aboud et al. 2021). Histopathological screening demonstrated extensive hepatic damage in MSG-treated group as the presence of dilated central vein, disarranged hepatic strands and infiltration of inflammatory cells associated with some apoptotic hepatocytes, which is in harmony with the biochemical findings and agrees with the previous studies (Elbassuoni et al. 2018, Shukry et al. 2020). Owing to the dissociation of MSG into L-glutamate which is transformed into glutamine, the later accumulates in hepatocytes resulted in its damage, and release of ALT and AST enzymes into blood stream (Elbassuoni et al. 2018). Moreover, the ammonium ions created by MSG trigger the formation of ROS that react with polyunsaturated fatty acids in hepatic cell membrane with consequent membrane damage and release of hepatic enzymes (Shukry et al. 2020). On the other hand, PCA preserved the functional as well as the structural integrity of the hepatic cellular membrane as demonstrated by restoring serum levels of AST and ALT enzymes and the pathological alterations. These findings reveal the membrane stabilizing activity of PCA and support former results of the hepatoprotective role of PCA (Adefegha et al. 2015, Ibitoye \&Ajiboye 2020, Radhiga et al. 2016).

Linked with the aforementioned alterations, we observed higher levels of glucose, TC and TG in MSGexposed rats. Our findings are in harmony with previous studies (Ibegbulem et al. 2016, Seiva et al. 2012, Shukry et al. 2020). Since MSG interfere with the hepatic functional status, the hepatic metabolism of lipoproteins may be negatively affected by MSG (Ibegbulem et al. 2016). Further, MSG could activate coenzyme A reductase, the limiting factor of cholesterol synthesis, which in turn increase serum TG, and TC (Shukry et al. 2020). High blood glucose level possibly attributed to encouragement of hepatic gluconeogenesis as well as low tissue insulin sensitivity (Seiva et al. 2012). On the other hand, concomitant PCA administration with MSG provoked potent hypolipidemic and hypoglycemic activities which agree with recent studies (El-Sonbaty et al. 2019, Li et al. 2020). PCA showed notable decrease in the activity of pancreatic lipase that is essential for absorption of triglycerides from the gastrointestinal tract (Li et al. 2020). Similar results were previously reported in diabetic, and D-galactosamine-exposed rats (Harini \&Pugalendi 2010, Radhiga et al. 2016). Also, PCA displayed marked decreases in lipid profile biomarkers associated with coronary artery disease in rats fed on high fat and fructose diet (Li et al. 2020).

To assess renal functionality in response to MSG administration, serum levels of urea and creatinine were measured in our study. Compared to the control group, significant increases were recorded in urea, and creatinine in MSG-treated group and these are in agreement with previous studies (del Carmen Contini et 
al. 2017, Elbassuoni et al. 2018). Moreover, renal histopathological finding revealed swollen glomeruli, vacuolar degeneration and desquamation. Renal damage in MSG exposed rats may refer to the damage in convoluted tubules and Bowman's corpuscles. In addition, MSG was reported to alter the tubular reabsorption, glomerular filtration rate and renal blood flow (Sharma 2015). All these factors may be endorsed for the nephrotoxicity of MSG as a result of functional and cellular damage. However, administration of PCA notably lessened the serum levels of renal function markers, thus indicating the renoprotection against MSG-induced renal toxicity in rats. These results validate former studies that reported the significant renal protection of PCA against chemicals-induced nephrotoxicity (Molehin et al. 2019, Owumi et al. 2019).

Supporting former studies, MSG reported to exert a pro-oxidant effect on the liver and kidney that is verified by the marked increase in MDA contents concomitant with notable decreases in antioxidant enzymatic activities of SOD, CAT, GR, GPx and GSH levels in the MSG-treated group (del Carmen Contini et al. 2017, Eid et al. 2019, Elbassuoni et al. 2018, Shukry et al. 2020). Moreover, Sharma (Sharma 2015) stated that high glutamate level induce overproduction of ROS in the renal tissue through activation of aketoglutarate dehydrogenase which is a potential inducer for ROS generation. The kidney tissue is vulnerable to lipid peroxidation by ROS due to its richness by long-chain polyunsaturated fatty acids (Elbassuoni et al. 2018). Therefore, oxidative damage is involved in tissue damage and this is confirmed by hepatic and renal damage on histopathological examination.

Nrf2/antioxidant response element (ARE) signaling pathway is one of the crucial cellular defense strategies to combat oxidative stress condition (Albarakati et al. 2020, Kassab et al. 2020). Normally, Nrf2 is inactive and combined with Kelch-like ECH-associated protein-1 (KEAP-1) in the cytoplasm but, in cases of oxidative stress status, Nrf2 translocate to the nucleus to bind ARE. Such binding elicits the downstream activation of antioxidant and detoxification enzymes to restore cell homeostasis status (Gao et al. 2018). In our study, marked upregulation in the expression of hepatic and renal Nrf2 in MSGexposed group was recorded as compared with the control. These results are in agreement with Gao et al. (Gao et al. 2018) who reported marked decreases in both mRNA and protein expressions of Nrf2 in response to MSG exposure in mice. In all, our data showed that MSG induced oxidative damage via downregulation of Nrf2 expression level associated with attenuated antioxidant defense and elevated lipid peroxidation level in hepatic and renal tissues.

Administration of PCA alleviated MSG-induced oxidative stress that was indicated by marked rises in the antioxidant enzymes activities and the level of GSH in both organs in addition to significant decreases in MDA levels. Studies have shown that the antioxidant potential of PCA is ten times than that of atocopherol (Song et al. 2020). The existence of hydroxyl groups in the chemical structure of PCA render it as a hydrogen atom donor for reduction of peroxyl radicals and halt their injurious action on the cellular membrane and cellular components (Owumi et al. 2019). These results are consistent with previous investigations that stated the protective effects of PCA against oxidative damage in liver and kidney in rat models (El-Sonbaty et al. 2019, Ibitoye \&Ajiboye 2020, Molehin et al. 2019). PCA stimulates the activities of endogenous antioxidant enzymes, as CAT, SOD, GST, GR, and GPx as well as decreasing levels of ROS, 
and MDA (Li et al. 2021a, Song et al. 2020). Additionally, PCA mediated-hepatorenal protection may be endorsed for marked elevation in GSH level that increase the cellular GSH bioavailability to scavenge free radicals generated by MSG as reported by former authors (Farombi et al. 2016, Owumi et al. 2019).

To further illustrate the antioxidant potential of PCA on liver and kidney of MSG-treated rats, the gene expression of Nrf2 was investigated. PCA induced marked upregulation in Nrf2 pathway that is responsible for the increased enzymatic activities of SOD, CAT, and this consistent with previous studies (Ibitoye \&Ajiboye 2020, Varì et al. 2011). The up-regulation of Nrf-2 expression by PCA results in a massive translocation to the nucleus, where it can binds to the ARE sequences, inducing the gene expression encoding for the majority of phase 2 detoxifying and antioxidant enzymes (Varì et al. 2011).

Furthermore, MSG has been shown to trigger inflammatory responses evidenced by elevated IL-1b and TNF-a levels and histopathological findings in the liver and kidney of exposed rats that is similar to what has been reported previously (Banerjee et al. 2020, Mirzakhani et al. 2020). Oxidative stress has been shown to enhance pro-inflammatory gene expression which is associated with elevated inflammatory cytokines (TNF-a, and IL-1 $\beta$ ) (Al-Megrin et al. 2020). Also, it was reported that excess exposure to exogenous glutamate enhanced the transcriptional levels of pro-inflammatory cytokines in brain and intestine (Xu et al. 2005). Roman-Ramos et al. (Roman-Ramos et al. 2011) found that MSG exposure stimulates the activation of peroxisome proliferator-activated receptors which control the proinflammatory cytokine signaling pathways in hepatic and fatty tissues. TNF-a triggers the transcription factor NF-KB, critical regulator for inflammation, which is translocated to the nuclear with consequent activation of target inflammatory genes. In our study, marked increases in levels of hepatic and renal NFKB were observed in MSG-treated group. Banerjee et al. (Banerjee et al. 2020) reported an increase in NFKB (p65) immune reaction in hepatic and cardiac tissues of MSG-fed rats.

On the contrary, PCA administration decreased the levels of IL-1beta, TNF-alpha and NF-KB in liver and kidney of rat treated with MSG. Similar findings were reported in rats injected with methotrexate and cotreated with PCA (Owumi et al. 2019). PCA elicited significant anti-inflammatory activities in various animal models such as paw edema, cotton pellet granuloma and Freund's adjuvant arthritis (Lende et al. 2011). Further, marked down-regulation in inducible nitric oxide synthetase and cyclooxygenase-2 expressions were noticed in the kidney of doxorubicin-injected rats (Molehin et al. 2019). PCA employs its anti-inflammatory effect via decreasing of the production of inflammatory mediators via modulating their gene and protein expressions involving NF-KB, MAPKs and STAT3 signaling pathways (Kaewmool et al. 2020). This indicates that PCA restrained MSG-induced inflammatory responses in liver and kidney via reducing NF-KB translocation to the nucleus with consequent suppression of target genes encoding the proinflammatory cytokines.

Our study also focused on the protective properties of PCA against MSG-induced cell death and apoptosis. Apoptosis contributes to maintain the cell death and division balance. The oxidative stress played a fundamental role to start the apoptosis ( $\mathrm{Li}$ et al. 2021a). Kidneys and livers of MSG-treated rats showed elevated Bax levels and declined Bcl-2 levels that revealed marked induction of apoptosis and 
agrees with former authors (Banerjee et al. 2020, Elbassuoni et al. 2018, Hassan et al. 2020, Shukry et al. 2020). Excess glutamate encouraged the influx of $\mathrm{Ca}^{2+}$ which disrupts the internal mitochondrial membrane potential, with resultant disturbed mitochondrial permeability to apoptotic markers (Shukry et al. 2020). On the contrary, PCA co-treatment elicited a significant anti-apoptotic effect demonstrated by decreasing the level of Bax and increasing the level of Bcl-2 in liver and kidney of MSG-received rats. Bcl-2 is a negative regulator of cellular death that protects cells against apoptotic damage, while Bax is a positive regulator of cellular death that promotes or accelerates cell death. Moreover, upregulated $\mathrm{Bcl}-2$ hinder the mitochondrial release of cytochrome-c to the cytosol, thus suppressing the caspases cascade and apoptosis (Liu et al. 2008). Bcl-2 also has been shown to reduce apoptosis by regulating ion transport and averting the collapse of mitochondrial membrane potential mediated by chemical agents (Guan et al. 2006). Marked decreases were noticed in caspase-3 activities in the liver and kidney of MTXtreated rats following PCA that signify its antagonistic effect against apoptotic cell death (Owumi et al. 2019). In vitro study revealed that PCA notably inhibited $\mathrm{H}_{2} \mathrm{O}_{2}$-induced platelet apoptosis by modulating caspase-9 and caspase-3, Bax, Bcl-xL, and cytochrome-c with involvement of PI3K/Akt/GSK3 $\beta$ Signaling pathway (Ya et al. 2021). Anti-apoptotic activity of PCA was reported previously against various chemicals and toxic compounds (Al Olayan et al. 2020, Guan et al. 2006, Li et al. 2021a, Liu et al. 2008).

\section{Conclusion}

In summary, this study emphasizes that administration of MSG above the reported safe limit produced liver and kidney disorders that is mediated by oxidative damage, inflammation and apoptotic changes. On the other side, PCA restored markedly the MSG-induced injuries by boosting the endogenous antioxidant enzymes and GSH level together with inhibition of lipid peroxidation. In addition, PCA lessened tissue inflammation, apoptosis and hyperlipidemia. Hepatoprotective and renoprotective effects of PCA may be endorsed for activation of Nrf2 antioxidant pathway and suppression of NF-kB signaling pathway. Therefore, foods with over MSG concentration can be fortified with addition of PCA to overwhelm its undesirable systemic effects.

\section{Declarations}

\section{Funding}

Not applicable

\section{Compliance with ethical standards Conflict of interest}

The author declares that there is no conflict of interest.

\section{Ethical approval}

All procedures were performed following the policies and guidelines of the Committee of Research Ethics for Laboratory Animal Care, Faculty of Science, Department of Zoology, Helwan University (Cairo, Egypt; 
Permit Number: HU2020/Z/RKA1020-03).

\section{Consent to Participate}

Not applicable.

\section{Consent to Publish}

Consented.

\section{Acknowledgment}

This work was supported by Taif University Researchers Supporting Program (Project number: TURSP2020/153), Taif University, Saudi Arabia.

\section{Authors' contributions}

Maha S. Lokman, Rami B. Kassab, Ali O. Al-Ghamdy and Abdulrahman Theyab: animal treatments, biochemical and methodology; Ahmad H. Mufti, Mohammad Algahtani, Ehab M. Abdella and Ola A. Habotta: visualization, investigation, and histological examinations; Heba A. Elmasry, Khalaf F. Alsharif, Maha A. Alshiekheid and Ashraf Albrakati: writing- reviewing and editing; Mohamed M. Omran, Amira A. Bauomy, Roua S. Baty, Khalid E. Hassan, Ahmed E. Abdel Moneim and Heba A. Elmasry: conceptualization, validation, and supervision. All authors participated in the design, interpretation of the studies, and analysis of the data and review of the manuscript.

\section{Availability of data and materials}

Available upon request.

\section{References}

Acar A Ameliorative effects of cape gooseberry (Physalis peruviana L.) against monosodium glutamate (MSG)-induced toxicity: genetic and biochemical approach. Environmental Science and Pollution Research, 1-15

Adefegha SA, Omojokun OS, Oboh G (2015): Modulatory effect of protocatechuic acid on cadmium induced nephrotoxicity and hepatoxicity in rats in vivo. Springerplus 4, 1-7

Aebi H (1984): Catalase in vitro. Methods in enzymology 105, 121-6

Al-Megrin WA, Alkhuriji AF, Yousef AOS, Metwally DM, Habotta OA, Kassab RB, Abdel Moneim AE, ElKhadragy MF (2020): Antagonistic efficacy of luteolin against lead acetate exposure-associated with hepatotoxicity is mediated via antioxidant, anti-inflammatory, and anti-apoptotic activities. Antioxidants 9,10 
Al Aboud D, Baty RS, Alsharif KF, Hassan KE, Zhery AS, Habotta OA, Elmahallawy EK, Amin HK, Moneim AEA, Kassab RB (2021): Protective efficacy of thymoquinone or ebselen separately against arsenicinduced hepatotoxicity in rat. Environmental Science and Pollution Research 28, 6195-6206

Al Olayan EM, Aloufi AS, AlAmri OD, El-Habit OH, Abdel Moneim AE (2020): Protocatechuic acid mitigates cadmium-induced neurotoxicity in rats: Role of oxidative stress, inflammation and apoptosis. The Science of the total environment 723, 137969

Albarakati AJA, Baty RS, Aljoudi AM, Habotta OA, Elmahallawy EK, Kassab RB, Moneim AEA (2020): Luteolin protects against lead acetate-induced nephrotoxicity through antioxidant, anti-inflammatory, antiapoptotic, and Nrf2/HO-1 signaling pathways. Molecular biology reports, 1-13

Albrahim T, Binobead MA (2018): Roles of Moringa oleifera leaf extract in improving the impact of high dietary intake of monosodium glutamate-induced liver toxicity, oxidative stress, genotoxicity, DNA damage, and PCNA alterations in male rats. Oxidative medicine and cellular longevity 2018

Banerjee A, Das D, Paul R, Roy S, Das U, Saha S, Dey S, Adhikary A, Mukherjee S, Maji BK (2020): Mechanistic study of attenuation of monosodium glutamate mixed high lipid diet induced systemic damage in rats by Coccinia grandis. Scientific reports 10, 1-24

Celestino M, Valdez VB, Brun P, Castagliuolo I, Mucignat-Caretta C (2021): Differential effects of sodium chloride and monosodium glutamate on kidney of adult and aging mice. Scientific reports 11

del Carmen Contini M, Fabro A, Millen N, Benmelej A, Mahieu S (2017): Adverse effects in kidney function, antioxidant systems and histopathology in rats receiving monosodium glutamate diet. Experimental and Toxicologic Pathology 69, 547-556

Dixit SG, Rani P, Anand A, Khatri K, Chauhan R, Bharihoke V (2014): To study the effect of monosodium glutamate on histomorphometry of cortex of kidney in adult albino rats. Renal failure 36, 266-270

Eid RA, Al-Shraim M, Zaki MS, Kamar SS, Abdel Latif NS, Negm S, Al-Ani B, Haidara MA (2019): Vitamin E protects against monosodium glutamate-induced acute liver injury and hepatocyte ultrastructural alterations in rats. Ultrastructural pathology 43, 199-208

El-Khadragy MF, Al-Megrin WA, Alomar S, Alkhuriji AF, Metwally DM, Mahgoub S, Amin HK, Habotta OA, Moneim AEA, Albeltagy RS (2021): Chlorogenic acid abates male reproductive dysfunction in arsenicexposed mice via attenuation of testicular oxido-inflammatory stress and apoptotic responses. ChemicoBiological Interactions 333, 109333

El-Sonbaty YA, Suddek GM, Megahed N, Gameil NM (2019): Protocatechuic acid exhibits hepatoprotective, vasculoprotective, antioxidant and insulin-like effects in dexamethasone-induced insulin-resistant rats. Biochimie 167, 119-134 
Elbassuoni EA, Ragy MM, Ahmed SM (2018): Evidence of the protective effect of l-arginine and vitamin D against monosodium glutamate-induced liver and kidney dysfunction in rats. Biomedicine \& Pharmacotherapy $108,799-808$

Ellman GL (1959): Tissue sulfhydryl groups. Arch Biochem Biophys 82, 70-7

Factor VM, Kiss A, Woitach JT, Wirth PJ, Thorgeirsson SS (1998): Disruption of redox homeostasis in the transforming growth factor-alpha/c-myc transgenic mouse model of accelerated hepatocarcinogenesis. The Journal of biological chemistry $273,15846-53$

Farombi EO, Adedara IA, Awoyemi OV, Njoku CR, Micah GO, Esogwa CU, Owumi SE, Olopade JO (2016): Dietary protocatechuic acid ameliorates dextran sulphate sodium-induced ulcerative colitis and hepatotoxicity in rats. Food \& function 7, 913-921

Gao W, Xiao C, Hu J, Chen B, Wang C, Cui B, Deng P, Yang J, Deng Z (2018): Qing brick tea (QBT) aqueous extract protects monosodium glutamate-induced obese mice against metabolic syndrome and involves up-regulation Transcription Factor Nuclear Factor-Erythroid 2-Related Factor 2 (Nrf2) antioxidant pathway. Biomedicine \& pharmacotherapy = Biomedecine \& pharmacotherapie 103, 637-644

Gill SS, Pulido OM (2001): Glutamate receptors in peripheral tissues: current knowledge, future research, and implications for toxicology. Toxicologic pathology 29, 208-23

Guan S, Jiang B, Bao YM, An LJ (2006): Protocatechuic acid suppresses MPP+ -induced mitochondrial dysfunction and apoptotic cell death in PC12 cells. Food Chem Toxicol 44, 1659-66

Harini R, Pugalendi KV (2010): Antioxidant and antihyperlipidaemic activity of protocatechuic acid on streptozotocindiabetic rats. Redox Report 15, 71-80

Hassan HA, El-Kholy WM, El-Sawi MR, Galal NA, Ramadan MF (2020): Myrtle (Myrtus communis) leaf extract suppresses hepatotoxicity induced by monosodium glutamate and acrylamide through obstructing apoptosis, DNA fragmentation, and cell cycle arrest. Environmental Science and Pollution Research 27, 23188-23198

Ibegbulem CO, Chikezie PC, Ukoha Al, Opara CN (2016): Effects of diet containing monosodium glutamate on organ weights, acute blood steroidal sex hormone levels, lipid profile and erythrocyte antioxidant enzymes activities of rats. Journal of Acute Disease 5, 402-407

Ibitoye O, Ajiboye T (2020): Protocatechuic acid protects against menadione-induced liver damage by upregulating nuclear erythroid-related factor 2 . Drug and chemical toxicology $43,567-573$

Kaewmool C, Kongtawelert P, Phitak T, Pothacharoen P, Udomruk S (2020): Protocatechuic acid inhibits inflammatory responses in LPS-activated BV2 microglia via regulating SIRT1/NF-KB pathway contributed to the suppression of microglial activation-induced PC12 cell apoptosis. Journal of neuroimmunology 341,577164 
Kassab RB, Lokman MS, Daabo HMA, Gaber DA, Habotta OA, Hafez MM, Zhery AS, Moneim AEA, Fouda MS (2020): Ferulic acid influences Nrf2 activation to restore testicular tissue from cadmium-induced oxidative challenge, inflammation, and apoptosis in rats. Journal of food biochemistry 44, e13505

Lende AB, Kshirsagar AD, Deshpande AD, Muley MM, Patil RR, Bafna PA, Naik SR (2011): Antiinflammatory and analgesic activity of protocatechuic acid in rats and mice. Inflammopharmacology 19 , 255-63

Li L, Liu S, Tang H, Song S, Lu L, Zhang P, Li X (2020): Effects of protocatechuic acid on ameliorating lipid profiles and cardio-protection against coronary artery disease in high fat and fructose diet fed in rats. Journal of Veterinary Medical Science 82, 1387-1394

\section{Li Z, Liu Y, Wang F, Gao Z, Elhefny MA, Habotta OA, Abdel Moneim AE, Kassab RB (2021a):}

Neuroprotective effects of protocatechuic acid on sodium arsenate induced toxicity in mice: Role of oxidative stress, inflammation, and apoptosis. Chem Biol Interact 337, 109392

Li Z, Liu Y, Wang F, Gao Z, Elhefny MA, Habotta OA, Moneim AEA, Kassab RB (2021b): Neuroprotective effects of protocatechuic acid on sodium arsenate induced toxicity in mice: Role of oxidative stress, inflammation, and apoptosis. Chemico-biological interactions 337, 109392

Lin C-Y, Tsai S-J, Huang C-S, Yin M-C (2011): Antiglycative effects of protocatechuic acid in the kidneys of diabetic mice. Journal of agricultural and food chemistry 59, 5117-5124

Liu YM, Jiang B, Bao YM, An LJ (2008): Protocatechuic acid inhibits apoptosis by mitochondrial dysfunction in rotenone-induced PC12 cells. Toxicology in vitro : an international journal published in association with BIBRA 22, 430-7

Mahieu S, Klug M, Millen N, Fabro A, Benmelej A, del Carmen Contini M (2016): Monosodium glutamate intake affect the function of the kidney through NMDA receptor. Life sciences 149, 114-119

Mekkawy AM, Ahmed YH, El-Sakhawy MA (2020): Ameliorative effect of Nigella sativa oil and vitamin C on the thyroid gland and cerebellum of adult male albino rats exposed to Monosodium glutamate (histological, immunohistochemical and biochemical studies). Tissue and Cell 66, 101391

Mirzakhani N, Farshid AA, Tamaddonfard E, Tehrani A, Imani M (2020): Comparison of the effects of hydroalcoholic extract of Capparis spinosa fruit, quercetin and vitamin $E$ on monosodium glutamateinduced toxicity in rats. Veterinary research forum : an international quarterly journal 11, 127-134

Molehin OR, Adeyanju AA, Adefegha SA, Oyeyemi AO, Idowu KA (2019): Protective mechanisms of protocatechuic acid against doxorubicin-induced nephrotoxicity in rat model. Journal of basic and clinical physiology and pharmacology 30

Nahok K, Li JV, Phetcharaburanin J, Abdul H, Wongkham C, Thanan R, Silsirivanit A, Anutrakulchai S, Selmi C, Cha'on U (2019): Monosodium Glutamate (MSG) Renders Alkalinizing Properties and Its Urinary 
Metabolic Markers of MSG Consumption in Rats. Biomolecules 9, 542

Ohkawa H, Ohishi N, Yagi K (1979): Assay for lipid peroxides in animal tissues by thiobarbituric acid reaction. Anal Biochem 95, 351-8

Owumi S, Ajijola I, Agbeti O (2019): Hepatorenal protective effects of protocatechuic acid in rats administered with anticancer drug methotrexate. Human \& experimental toxicology 38, 1254-1265

Paglia DE, Valentine WN (1967): Studies on the quantitative and qualitative characterization of erythrocyte glutathione peroxidase. J Lab Clin Med 70, 158-69

Pfaffl MW (2001): A new mathematical model for relative quantification in real-time RT-PCR. Nucleic Acids Res 29, e45

Radhiga T, Sundaresan A, Viswanathan P, Pugalendi KV (2016): Effect of protocatechuic acid on lipid profile and DNA damage in D-galactosamine-induced hepatotoxic rats. Journal of basic and clinical physiology and pharmacology $27,505-514$

Reitman S, Frankel S (1957): A colorimetric method for the determination of serum glutamic oxalacetic and glutamic pyruvic transaminases. American journal of clinical pathology $28,56-63$

Roman-Ramos R, Almanza-Perez JC, Garcia-Macedo R, Blancas-Flores G, Fortis-Barrera A, Jasso El, Garcia-Lorenzana M, Campos-Sepulveda AE, Cruz M, Alarcon-Aguilar FJ (2011): Monosodium glutamate neonatal intoxication associated with obesity in adult stage is characterized by chronic inflammation and increased mRNA expression of peroxisome proliferator-activated receptors in mice. Basic Clin Pharmacol Toxicol 108, 406-13

Sasaki Y, Shimada T, lizuka S, Suzuki W, Makihara H, Teraoka R, Tsuneyama K, Hokao R, Aburada M (2011): Effects of bezafibrate in nonalcoholic steatohepatitis model mice with monosodium glutamateinduced metabolic syndrome. European journal of pharmacology 662, 1-8

Seiva FR, Chuffa LGA, Braga CP, Amorim JPA, Fernandes AAH (2012): Quercetin ameliorates glucose and lipid metabolism and improves antioxidant status in postnatally monosodium glutamate-induced metabolic alterations. Food and Chemical Toxicology 50, 3556-3561

Sharma A, Wongkham C, Prasongwattana V, Boonnate P, Thanan R, Reungjui S, Cha'on U (2014): Proteomic analysis of kidney in rats chronically exposed to monosodium glutamate. PLoS One 9, e116233

Sharma A (2015): Monosodium glutamate-induced oxidative kidney damage and possible mechanisms: a mini-review. Journal of biomedical science 22, 1-6

Shukry M, El-Shehawi AM, El-Kholy WM, Elsisy RA, Hamoda HS, Tohamy HG, Abumandour MM, Farrag FA (2020): Ameliorative effect of graviola (Annona muricata) on mono sodium glutamate-induced hepatic 
injury in rats: Antioxidant, apoptotic, anti-inflammatory, lipogenesis markers, and histopathological studies. Animals 10, 1996

Song J, He Y, Luo C, Feng B, Ran F, Xu H, Ci Z, Xu R, Han L, Zhang D (2020): New progress in the pharmacology of protocatechuic acid: A compound ingested in daily foods and herbs frequently and heavily. Pharmacol Res 161, 105109

Sun Y, Oberley LW, Li Y (1988): A simple method for clinical assay of superoxide dismutase. Clin Chem $34,497-500$

Trinder $\mathrm{P}$ (1969): Determination of glucose in blood using glucose oxidase with an alternative oxygen acceptor. Annals of clinical Biochemistry 6, 24-27

Varì R, D'Archivio M, Filesi C, Carotenuto S, Scazzocchio B, Santangelo C, Giovannini C, Masella R (2011): Protocatechuic acid induces antioxidant/detoxifying enzyme expression through JNK-mediated Nrf2 activation in murine macrophages. The Journal of Nutritional Biochemistry 22, 409-417

Xi Z, Chen X, Xu C, Wang B, Zhong Z, Sun Q, Sun Y, Bian L (2020): Protocatechuic acid attenuates brain edema and blood-brain barrier disruption after intracerebral hemorrhage in mice by promoting $\mathrm{Nrf} 2 / \mathrm{HO}-1$ pathway. Neuroreport 31, 1274-1282

Xu L, Sun J, Lu R, Ji Q, Xu J-G (2005): Effect of glutamate on inflammatory responses of intestine and brain after focal cerebral ischemia. World journal of gastroenterology: WJG 11, 733

Ya F, Li K, Chen H, Tian Z, Fan D, Shi Y, Song F, Xu X, Ling W, Adili R, Yang Y (2021): Protocatechuic Acid Protects Platelets from Apoptosis via Inhibiting Oxidative Stress-Mediated PI3K/Akt/GSK3 $\beta$ Signaling. Thrombosis and haemostasis

Yuan X, Fu Z, Ji P, Guo L, Al-Ghamdy AO, Alkandiri A, Habotta OA, Abdel Moneim AE, Kassab RB (2020): Selenium Nanoparticles Pre-Treatment Reverse Behavioral, Oxidative Damage, Neuronal Loss and Neurochemical Alterations in Pentylenetetrazole-Induced Epileptic Seizures in Mice. Int J Nanomedicine $15,6339-6353$

\section{Figures}




\section{Liver}
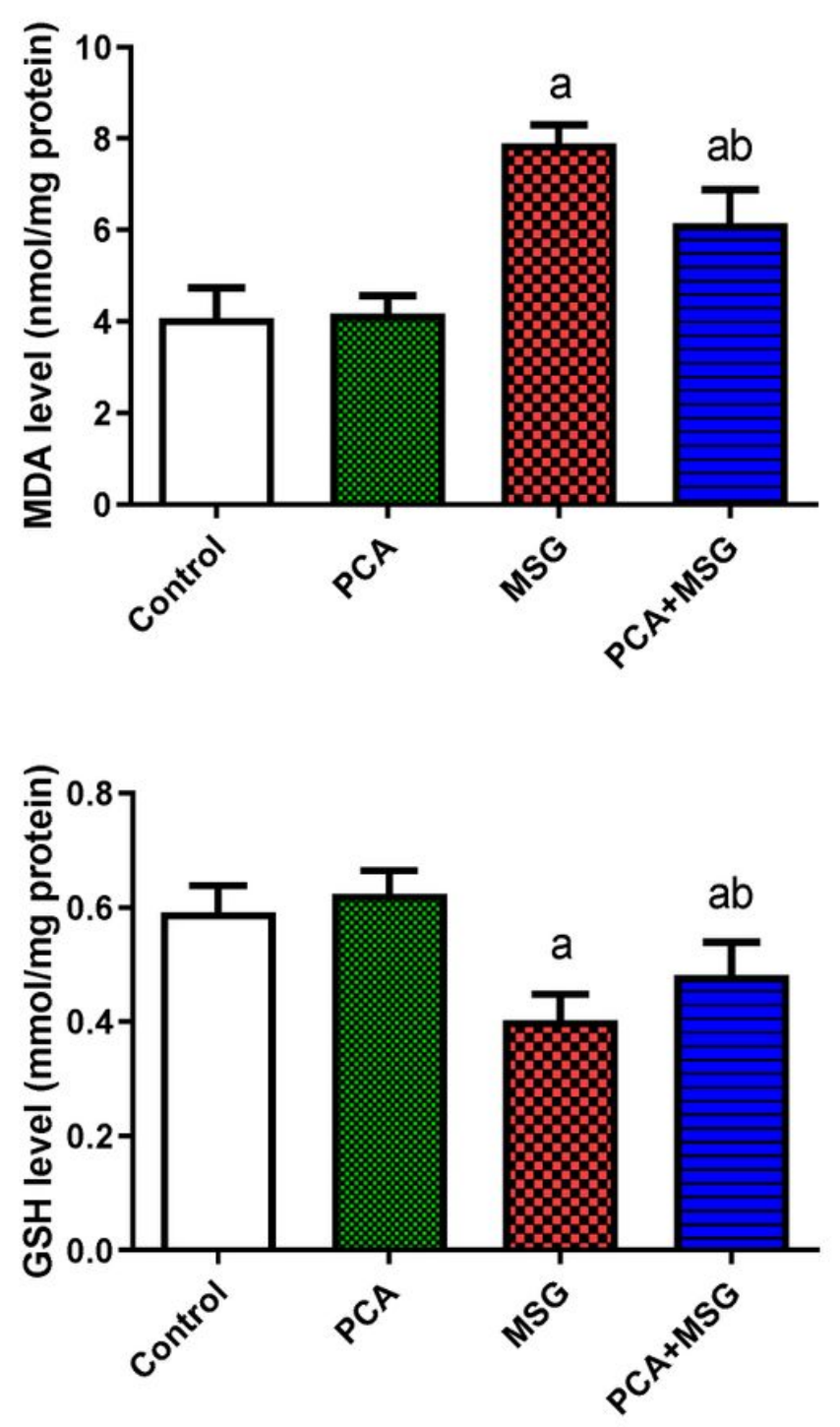

Kidney
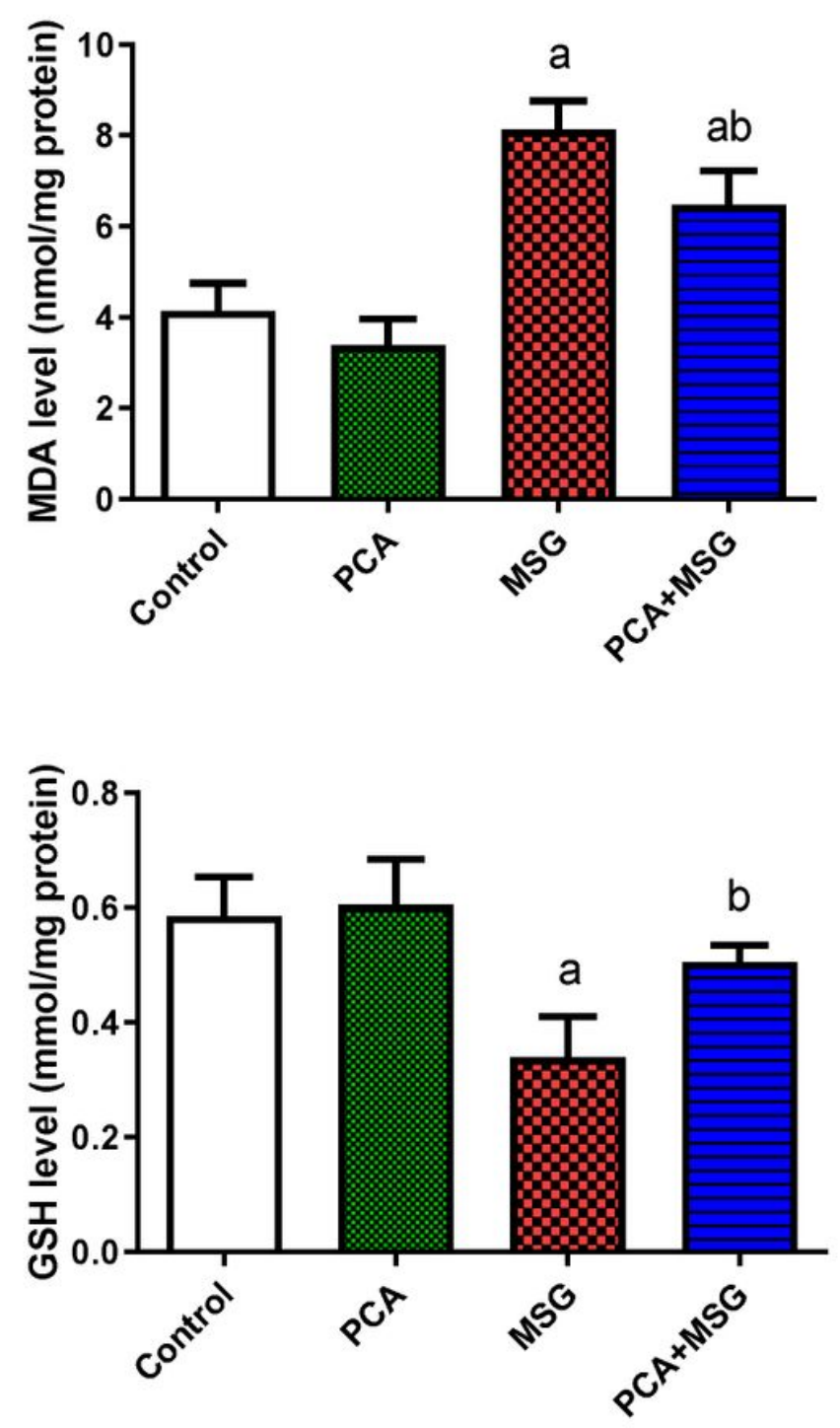

Figure 1

The effect of protocatechuic acid (PCA) on monosodium glutamate (MSG)-induced oxidative stress in hepatic and renal tissues in male rats. Each value represents mean $\pm S D(n=7)$. a $P<0.05$ versus the control rats, $b \mathrm{P}<0.05$ versus the MSG-treated rats. 


\section{Liver}
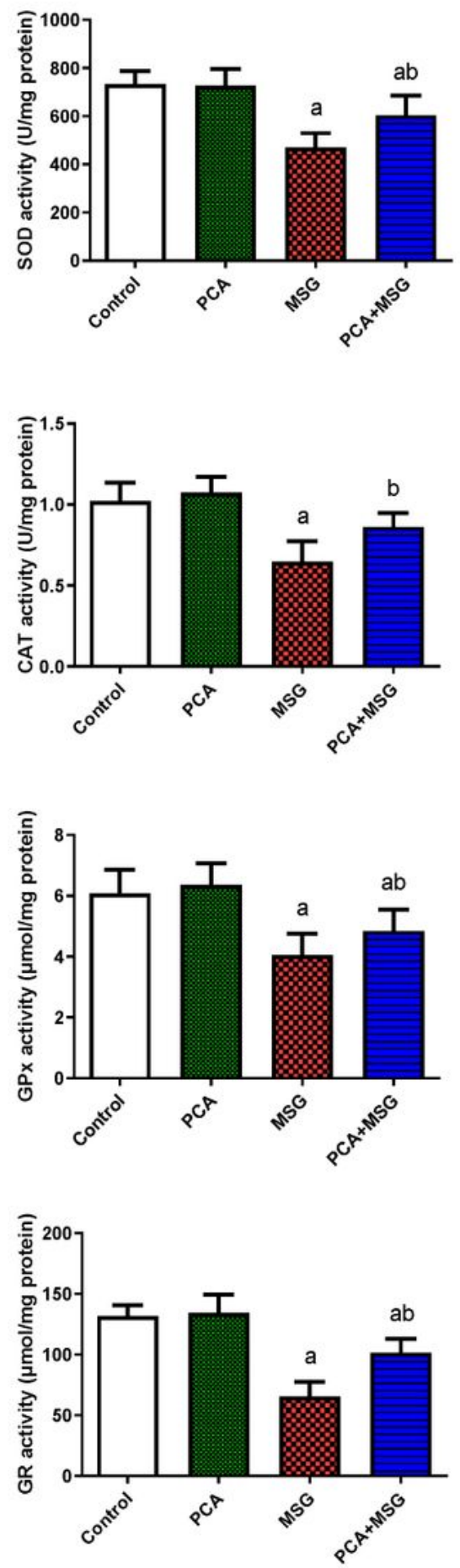

Kidney
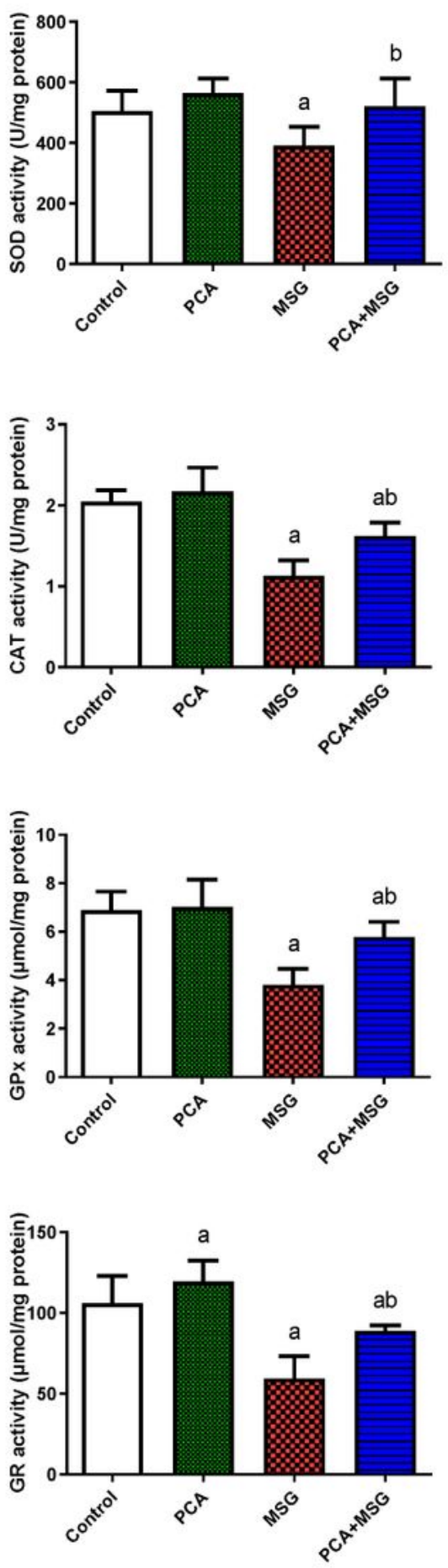

Figure 2

The effect of protocatechuic acid (PCA) on antioxidant enzyme activities (SOD, CAT, GPx, GR) in hepatic and renal tissues in monosodium glutamate (MSG)-treated rats. The enzyme activity values are presented as mean $\pm S D(n=7)$, a $P<0.05$ versus the control rats, $b P<0.05$ versus the MSG-treated rats. 
Liver

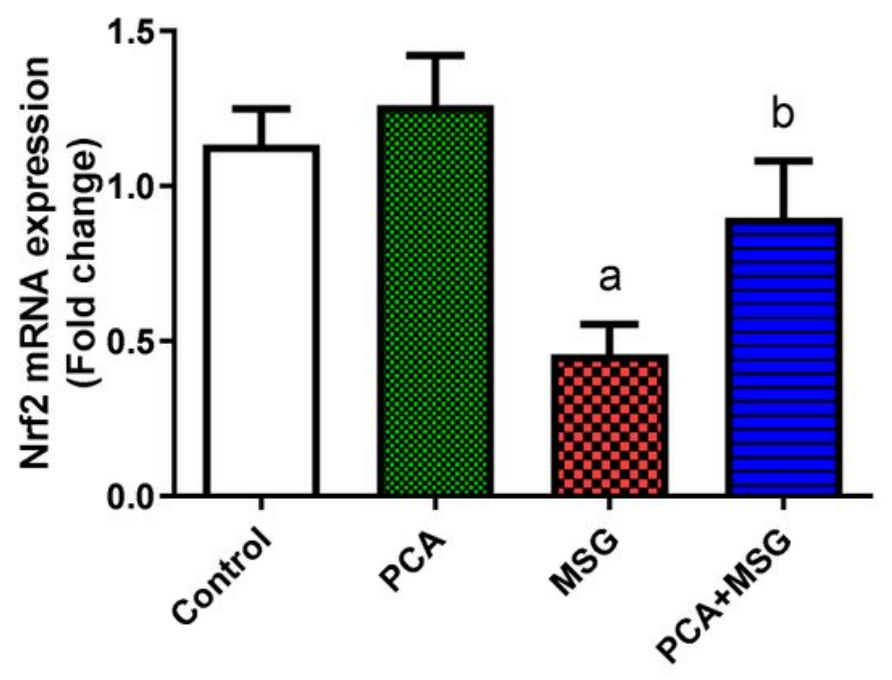

Kidney

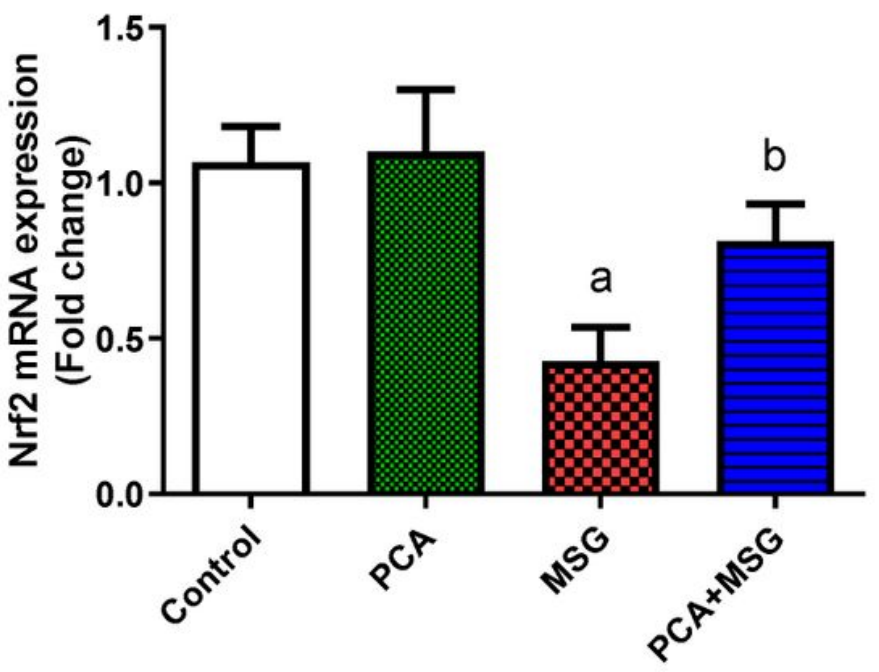

Figure 3

The effect of protocatechuic acid (PCA) on mRNA expression of Nfe2/2 in hepatic and renal tissues in monosodium glutamate (MSG)-treated rats. PCR results are expressed as mean \pm SD of triplicates that were normalized to the housekeeping Actb gene and represented as fold-change. a $P<0.05$ versus the control rats, $\mathrm{b} \mathrm{P}<0.05$ versus the MSG-treated rats. 

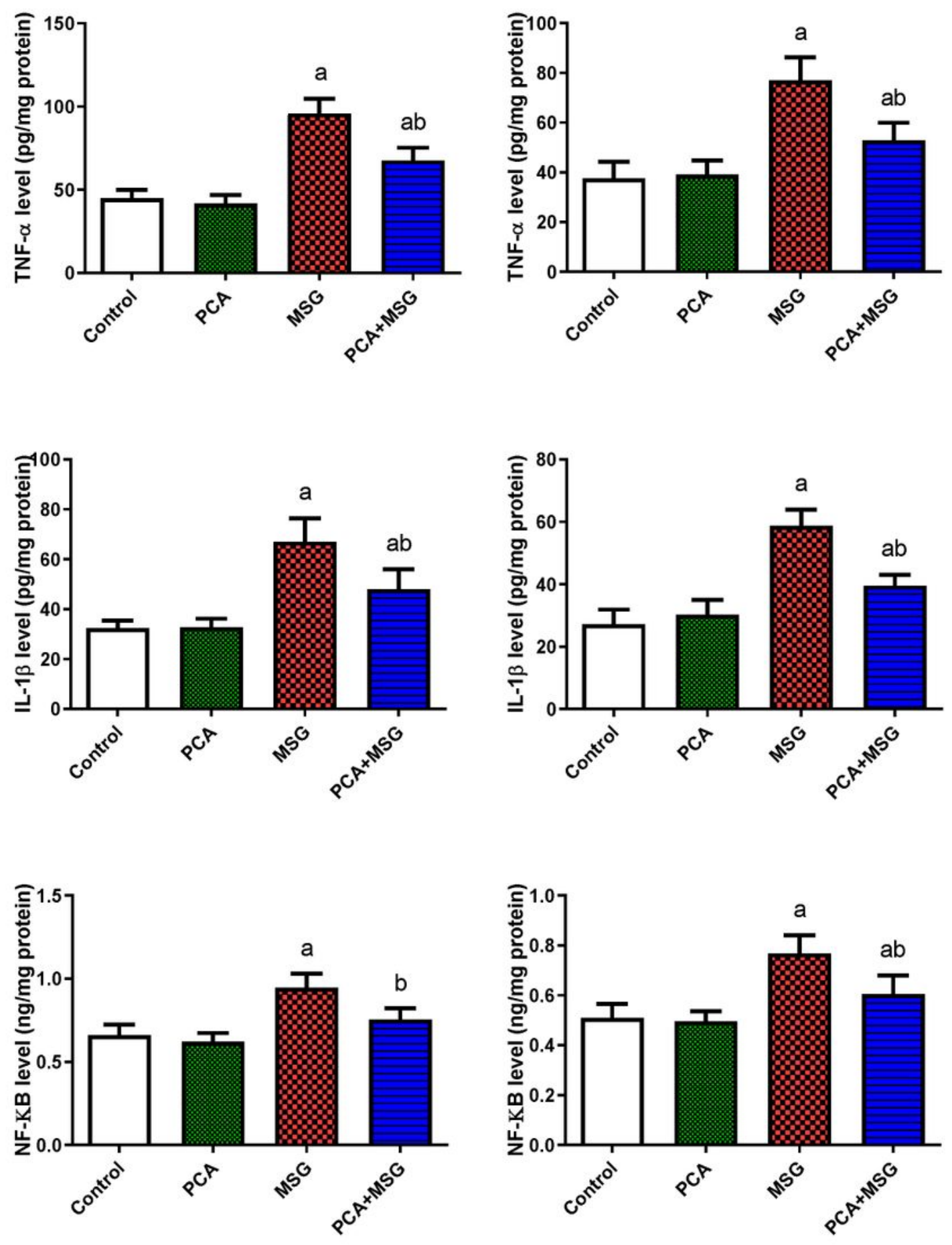

Figure 4

The effect of protocatechuic acid (PCA) on levels of IL-1b, TNF- $a$ and NF-KB in hepatic and renal tissues in monosodium glutamate (MSG)-treated rats. Each value represents mean $\pm S D(n=7)$. a $P<0.05$ versus the control rats, $\mathrm{b} P<0.05$ versus the MSG-treated rats. 
Liver
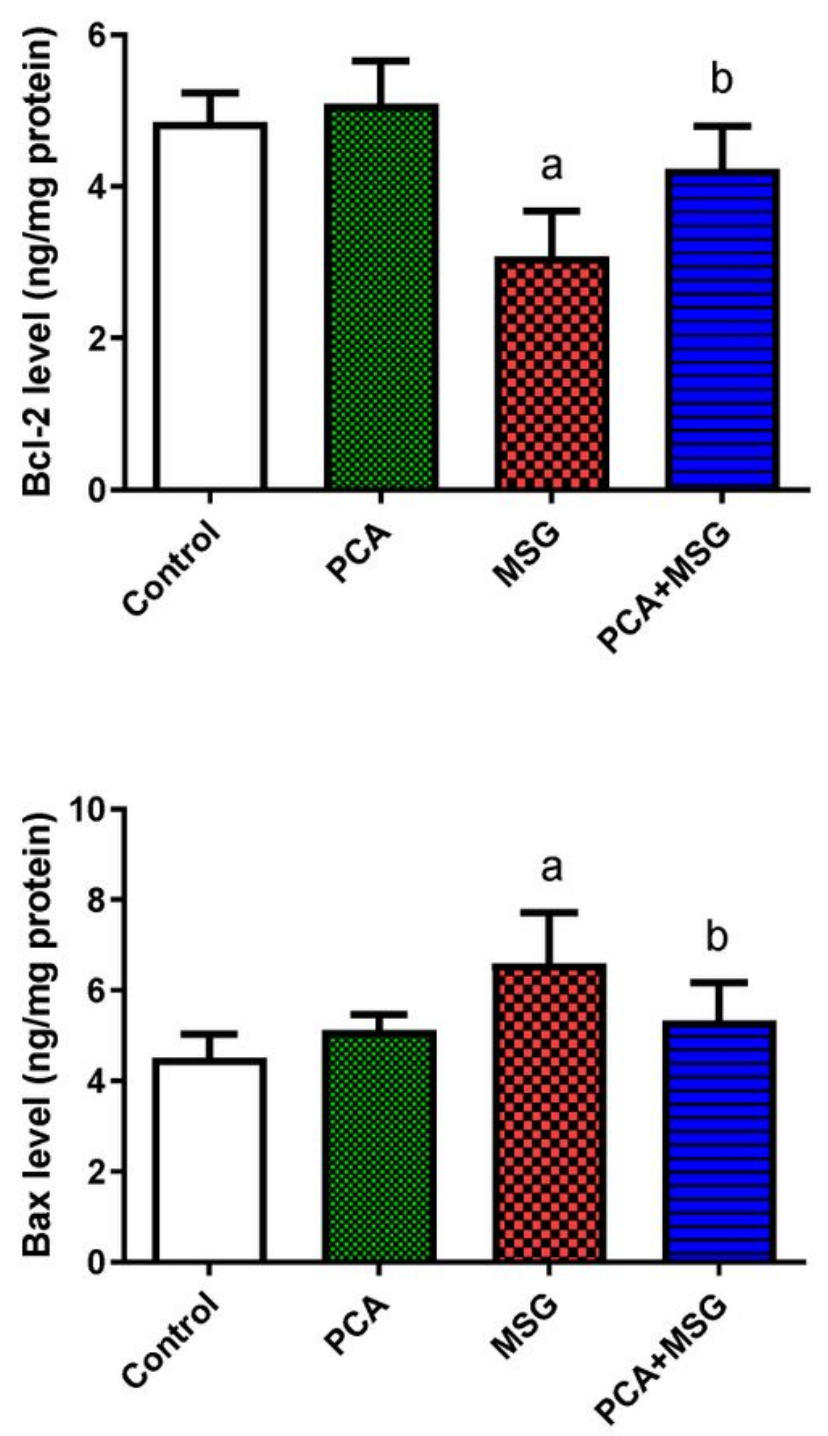

Kidney
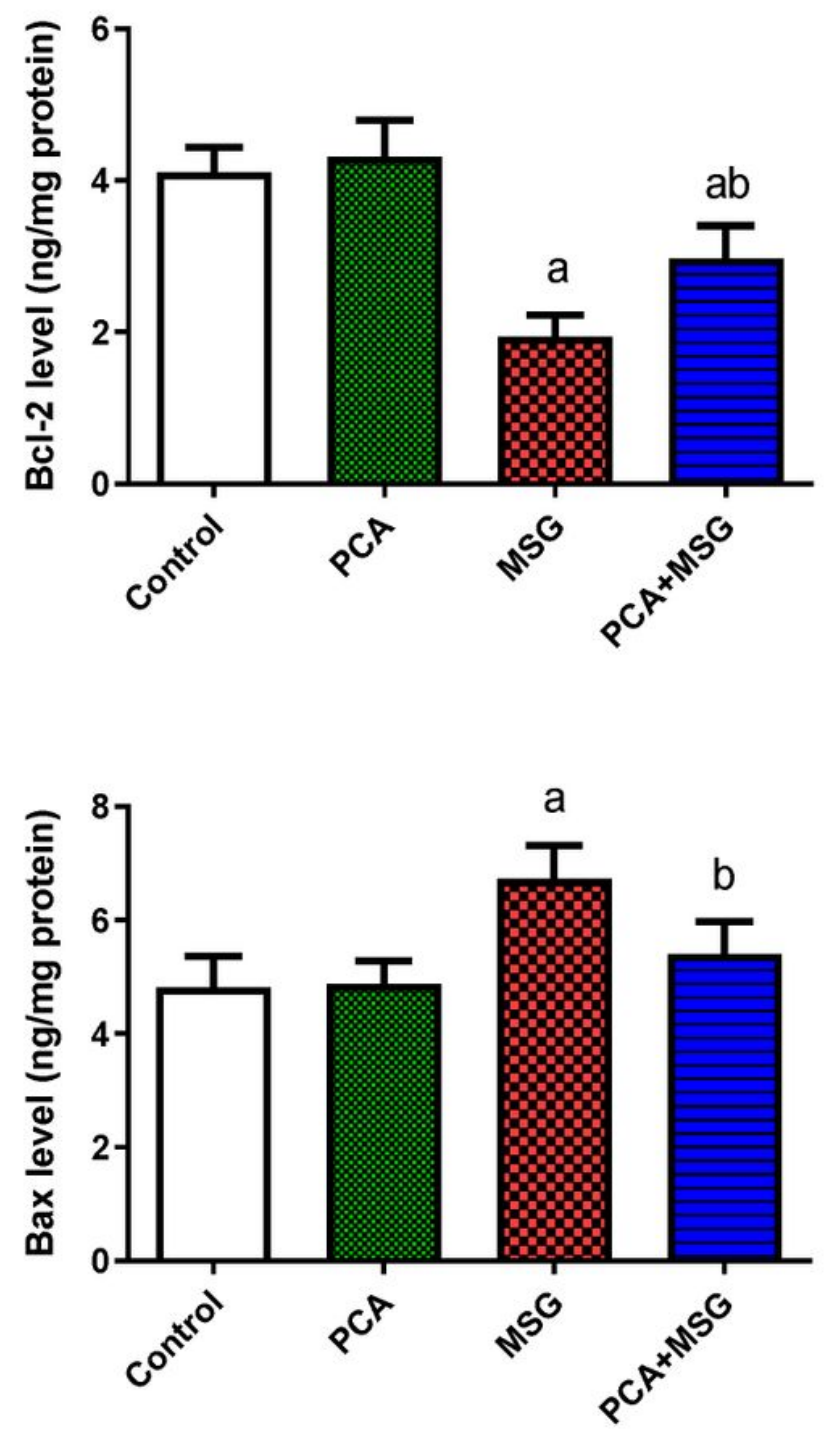

Figure 5

The effect of protocatechuic acid (PCA) on monosodium glutamate (MSG)-induced apoptosis in the hepatic and renal tissues in male rats $(n=7)$. Bax and $B c l-2$ values are presented as mean $\pm S D(n=7)$. a $\mathrm{P}<0.05$ versus the control rats, $\mathrm{b} P<0.05$ versus the MSG-treated rats. 

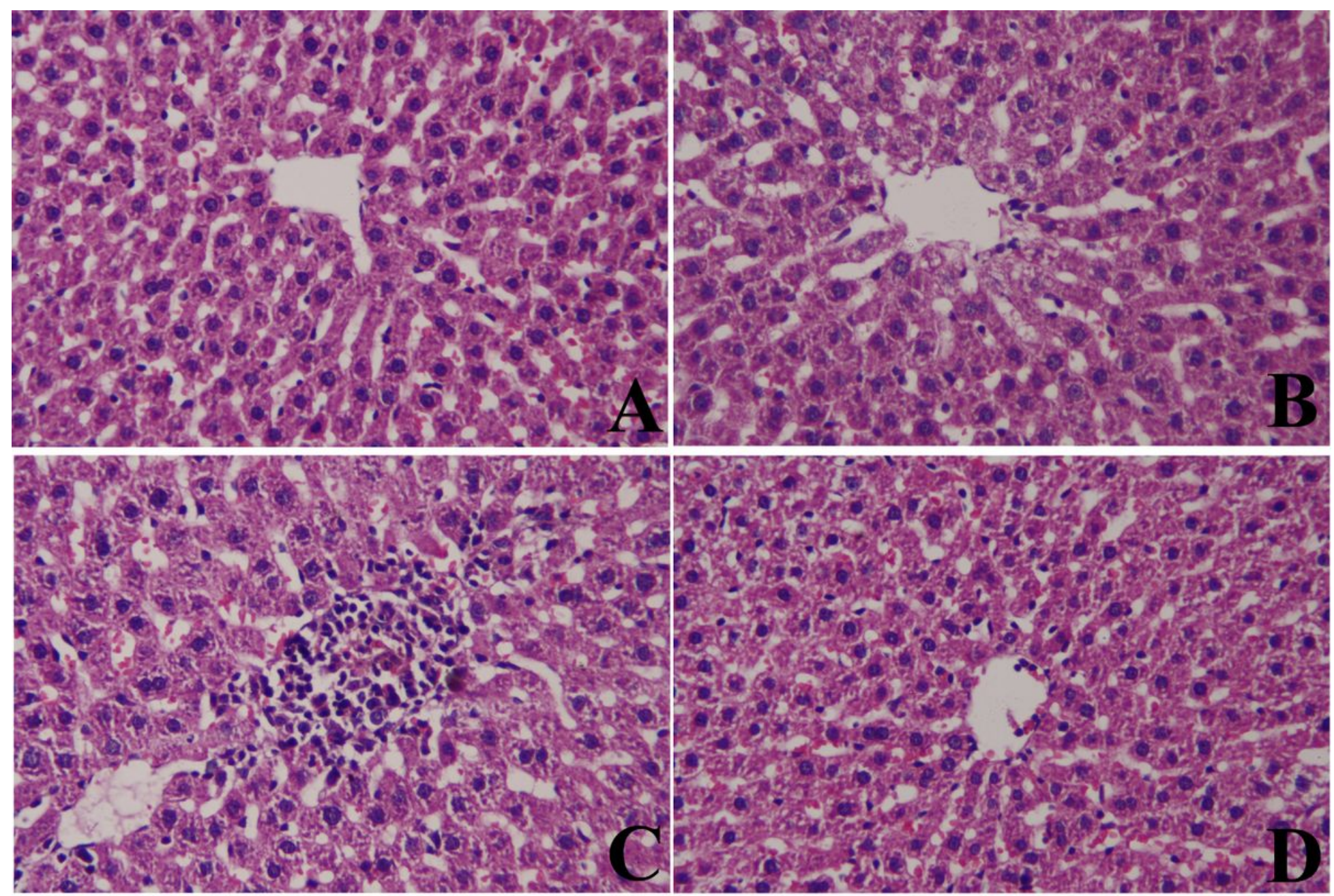

\section{Figure 6}

H\&E stained micrographs of hepatic tissues from (A) control, (B) PCA, (C) MSG, and (D) PCA + MSGtreated male rats. $(A, B)$ : showing a normal hepatic tissue structure. (C): marked dilatation of hepatic sinusoids, and hepatocyte vacuolation with infiltration of inflammatory cells. Besides, there were abundant small fragmented pyknotic nuclei and apoptotic hepatocytes (D) Co-treatment with PCA showed no visible lesions. Scale bar $=100 \mu \mathrm{m}$. 

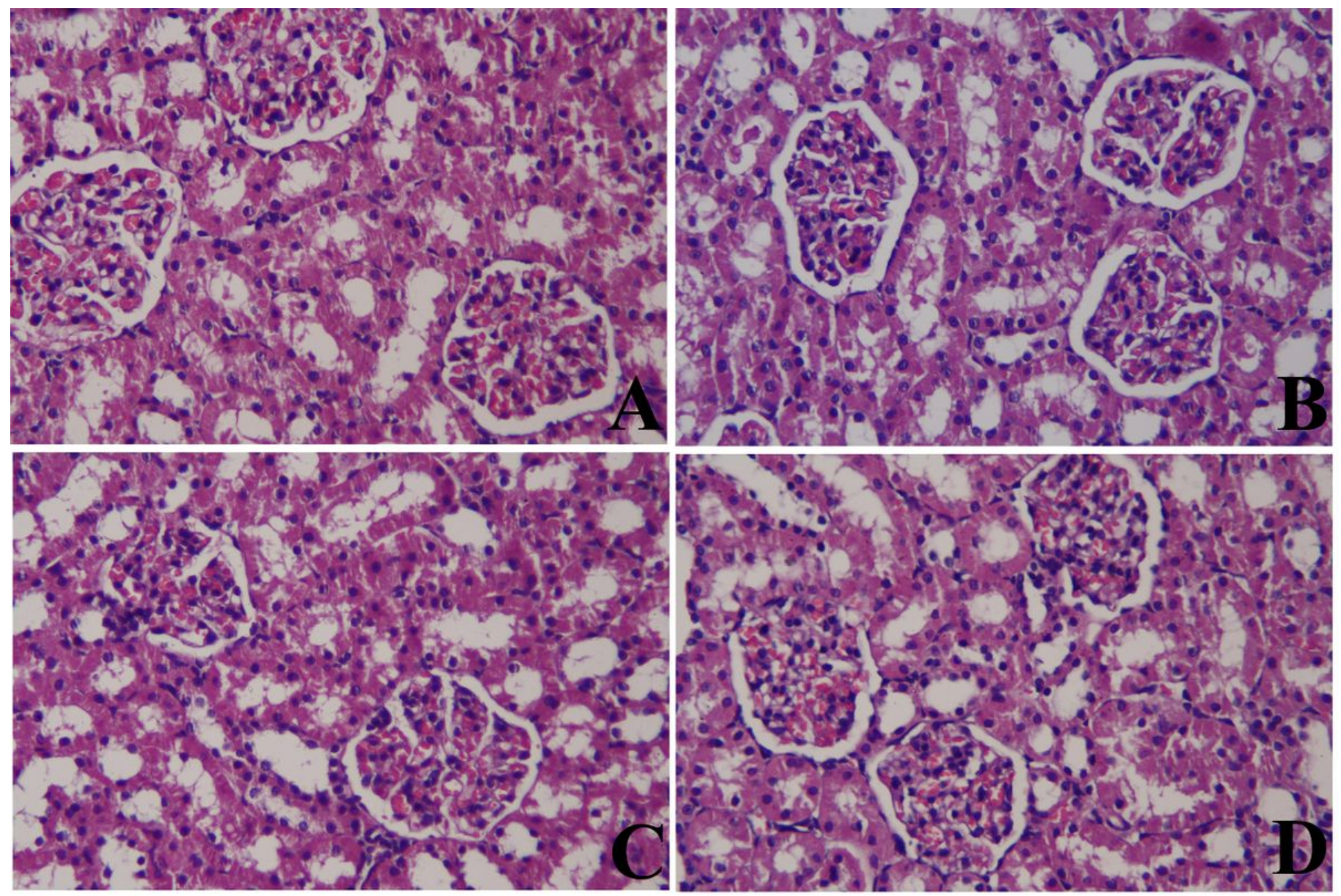

Figure 7

H\&E stained micrographs of renal tissues from (A) control, (B) PCA, (C) MSG, and (D) PCA + MSG-treated male rats. $(A, B)$ showing a normal renal tissue structure. $(C)$ renal tissue showed marked swelling in the glomeruli, decreased Bowman's spaces, vacuolar degeneration in addition to infiltration of inflammatory cells in the interstitial tissue. (D) Co-treatment with PCA showed no visible lesions. Scale bar $=100 \mu \mathrm{m}$. 